\title{
A RACIONALIZAÇÃO DO TRABALHO PEDAGÓGICO E O USO DE RECURSOS AUDIOVISUAIS NA EDUCAÇÃO: UM OLHAR SOBRE A PEDAGOGIA TECNICISTA NO BRASIL
}

\author{
Evelyn Fernandes Azevedo Faheina ${ }^{1}$ \\ Universidade Federal da Paraíba (UFPB)
}

\section{RESUMO}

Este trabalho discute a tendência pedagógica tecnicista predominante no Brasil entre a segunda metade da década de 1960 e início de 1970. Seu objetivo é refletir sobre a racionalização do trabalho pedagógico difundido por tal tendência, assim como, compreender as razões pela qual a pedagogia tecnicista invocou a utilização de recursos audiovisuais na educação, sobretudo a TV, procurando, desse modo, instaurar um projeto de modernização no país e adequação às transformações tecnológicas da época. Do ponto de vista teórico-metodológico, este trabalho está situado na esteira da teoria do Capital Humano de Theodore Schultz (1967), na teoria comportamental de Skinner (1972) e nos desdobramentos editoriais da Revista Brasileira de Estudos Pedagógicos dos anos 1966, 1967 e 1969, focadas na discussão do uso de recursos audiovisuais na educação. Tal abordagem permite a configuração de profícuo instrumento no entendimento da pedagogia tecnicista, cuja ênfase recai, por um lado, na racionalização do trabalho pedagógico, fundamentadas nos princípios da racionalidade, da eficiência e da produtividade e, por outro lado, no reconhecimento da eficiência dos meios pedagógicos, em particular, os recursos audiovisuais fomentados a partir da segunda metade da década de 1960.

Palavras-chave: Pedagogia Tecnicista. Racionalização do Trabalho Pedagógico. Recursos Audiovisuais.

\section{THE RATIONALIZATION OF PEDAGOGICAL WORK AND THE USE OF AUDIOVISUAL RESOURCES IN EDUCATION: A LOOK ON THE TECHNICALITY PEDAGOGY IN BRAZIL}

\begin{abstract}
This paper discusses the trend toward technicist pedagogical predominant in Brazil between the second half of 1960 and beginning of 1970. Its objective is reflect about the rationalization of pedagogical work distributed by this trend, as well as, understand the reasons for which the pedagogy technicist invoked the use of audiovisual resources in education, especially the TV, in an attempt to, in this way, establish a project of modernize the country and adequacy to the technological transformations of the age. From a theoretical-methodological viewpoint, this work is situated in the wake of the Human Capital theory of Theodore Schultz (1967), in the behavioral theory of Skinner (1972) and in the unfolding editorials of the Brazilian Journal of Pedagogical Studies of the years 1966, 1967 and 1969, focused on discussion of the use of audiovisual resources in education. Such an approach allows the configuration of a fruitful tool in understanding of the pedagogy technicist, whose emphasis is, on the one hand, the rationalization of the pedagogical work, based on the principles of rationality, efficiency and productivity and, on the other hand, on recognition of the effectiveness of teaching methods, in particular, the audiovisual resources encouraged from the second half of 1960.
\end{abstract}

Revista HISTEDBR On-line, Campinas, n.43, p.92-102, set2011 - ISSN: 1676-2584 92 
Keywords: Technicality Pedagogy. Rationalization of Pedagogical Work. Audiovisual Resources.

O modelo econômico associado-dependente ${ }^{2}$ adotado no Brasil, a partir da segunda metade da década de 1960, colocou a educação como um dos fatores decisivos no processo de desenvolvimento do país. Entendia-se, com isso, que a educação exercia um papel indispensável na consolidação das relações econômicas capitalistas, devendo, por isso, se adequar ao "novo" projeto de modernização da sociedade (SAVIANI, 2007).

No bojo dessas idéias, a teoria do Capital Humano, formulada por Theodore Schultz $(1967)^{3}$, se difundiu entre profissionais de diferentes áreas como a Economia, a Administração e a Educação. Neste último campo, Schultz defendia a ideia de que a educação era considerada o maior investimento do capital humano e afirmava:

Sempre que a instrução elevar as futuras rendas dos estudantes, teremos um investimento. É um investimento no capital humano, sob a forma de habilidades adquiridas na escola [...]. Pode-se dizer, na verdade, que a capacidade produtiva do trabalho é, predominantemente, um meio de produção produzido. Nós "produzimos", assim, a nós mesmos e, nesse sentido, os "recursos humanos" são uma conseqüência de investimentos entre os quais a instrução é da maior importância (SCHULTZ, 1967, p. 25).

Segundo Schultz (1967), as pessoas deveriam valorizar suas capacidades, quer sejam como produtores, quer sejam como consumidores, pelo auto-investimento, transformando desse modo, seus padrões de acumulação de riquezas. Ele pressupunha que a educação elevaria as futuras rendas dos estudantes e, por isso, deveria ser vista como um investimento. É com base nesse entendimento que a educação brasileira começa a ser pensada por muitos educadores ${ }^{4}$ a partir da segunda metade da década de 1960. Assim, influenciados pela teoria do Capital Humano, muitos desses educadores passaram a considerar a escola como uma empresa especializada na produção da instrução/educação, cuja organização e administração se dariam em função da obtenção de lucro. E, com essa medida, a educação deveria acontecer de forma racional e eficiente, garantindo a objetivação do trabalho pedagógico.

Orientada pelos princípios da racionalidade, da eficiência e da produtividade, a teoria do Capital Humano ganhou ainda mais força no campo educacional na medida em que passou a ser incorporada à legislação vigente no final da década de 1960 e início de 1970 , com as reformas do ensino ${ }^{5}$. Embora tais reformas não sejam objetos de nossa reflexão nesse texto, discutiremos mais adiante como a tendência pedagógica tecnicista se estruturou no ensino brasileiro, provocando mudanças radicais em suas bases pedagógicas, tornando o ensino mecânico e racional ${ }^{6}$.

De acordo com a teoria skinneriana, as práticas educativas da pedagogia tecnicista visavam fortalecer ainda mais um projeto de educação eficiente, nos quais os currículos, materiais e técnicas didáticas deveriam ser aprimoradas e revisadas na perspectiva de garantir, também, a aprendizagem eficiente (SKINNER, 1972).

Nessa perspectiva, o uso de recursos audiovisuais ${ }^{7}$ na educação se apresentava como a "panacéia universal", pois, acreditava-se que os novos meios tecnológicos, sobretudo a televisão, revolucionaria a pedagogia e traria soluções para todos os males da metodologia e da didática da época. Acreditava-se que ao entrarem em contato com esses recursos, os alunos se apropriariam da própria realidade, até então vista e ensinada apenas nos livros escritos, dando ao ensino as "qualidades ativas" 8 que lhe faltava (GAL, 1966).

Revista HISTEDBR On-line, Campinas, n.43, p.92-102, set2011 - ISSN: 1676-2584 93 
Obviamente essa não era a visão unívoca da época. O advento da Indústria Cultural e, por conseguinte, das mídias de massas, fez eclodir, de um lado, estudos desenvolvidos por educadores que refletiam a relação entre a cultura e a comunicação nos processos educacionais e, de outro lado, ideias cuja centralidade ganhava força na crítica aos meios de comunicação de massa, com ênfase nos seus efeitos e nas ideologias a eles associados (CAMBI, 1999).

$\mathrm{Na}$ década de 1970, influenciadas pela teoria crítico-reprodutivista, educadores passaram a conceber a prática do uso dos meios de comunicação na educação como uma prática social não neutra, enfatizando que os efeitos produzidos por tais meios estavam associados à certa visão de mundo, ao poder de manipulação e à reprodução ideológica por eles veiculados.

Cambi (1999) ressalta que o surgimento dos meios de comunicação de massa, como a televisão, o vídeo e o cinema, empreenderam caminhos diversos para o campo educacional. De um lado, vinculadas às ideias de Adorno e Horkheimer, os meios de comunicação eram vistos como instrumentos deseducadores, alienantes e de atrofia da imaginação e da espontaneidade dos indivíduos e, de outro lado, em proximidade com a visão de Marshall Mc Luhan, os meios de comunicação iam se afirmando cada vez mais como meio pedagógico central e indispensável no mundo contemporâneo.

Assim, no que tange essa última perspectiva, Miranda (1996) ressalta que a ampliação dos meios de comunicação de massa e a necessidade de democratizar a cultura e o saber escolarizado produziram nos educadores a conscientização de trabalhar com esses meios de comunicação na educação. $O$ autor ainda nos lembra que a superação da "demonização" dos meios de comunicação, vistos como ideológicos por aqueles que compartilhavam da teoria reprodutivista e crítico - reprodutivista resultou em um percurso muito longo. Segundo ele, o abandono dessa abordagem favoreceu a concepção dos meios de comunicação como objetos de estudo que poderiam ser utilizados na escola. No entanto, o grande desafio era efetuar o uso pedagógico desses meios de forma "não-invasiva" e "não-deseducativa", mediante o qual fosse possível oferecer uma melhor qualidade educativa para os indivíduos, tanto do ponto de vista cultural, quanto do ponto de vista do conhecimento sistematizado.

Aliado a este desafio, entendemos a necessidade de avançar para além de uma visão instrumentalista e utilitarista do uso dos meios de comunicação na educação ${ }^{9}$. Veremos, mais adiante, que a concepção adotada pelos tecnicistas não conseguiu avançar nesse sentido, limitando-se, portanto, à incorporação do recurso audiovisual nos processos pedagógicos como uma forma meramente ilustrativa ou complementar do conhecimento e estritamente técnica.

Desse modo, pretendemos refletir no texto a racionalização do trabalho pedagógico, tão difundida pela pedagogia tecnicista entre a segunda metade da década de 1960 e início de 1970 e compreender as razões pelas quais tal tendência invocou a utilização de recursos audiovisuais na educação, sobretudo a TV, procurando, desse modo, instaurar um projeto de modernização no país e adequação às transformações tecnológicas da época.

\section{A racionalização do trabalho pedagógico}

Vimos que os elementos que deram forma à tendência pedagógica tecnicista no país incorreram a partir da segunda metade da década de 1960. Publicações como a de Theodor Schultz (1967) sobre a Teoria do Capital Humano, a teoria comportamental de Skinner (1972) e artigos em revistas brasileiras de educação ${ }^{10}$, refletiram expressivamente, no 
âmbito editorial, a predominância da pedagogia tecnicista até a década de 1970. Além disso, as reformas do ensino, ocorridas em finais dos anos 1960 e início de 1970, demonstraram como essa tendência educacional provocou mudanças na estrutura e na organização do trabalho pedagógico. Uma dessas mudanças ocorreu no próprio processo de ensino, tornando-o mecânico e racional, na perspectiva de minimizar ao máximo, os elementos e/ou fatores que pusessem em risco sua eficiência (FREITAG, 1980; ROMANELLI, 2002; SAVIANI, 2007). A respeito disto, Saviani (2007) nos lembra que a partir daí surgiram várias propostas pedagógicas que vieram a consolidar ainda mais a pedagogia tecnicista no país, a exemplo do enfoque sistêmico, microensino, telensino, instrução programada, máquinas de ensinar, entre outros.

Em “Tecnologia do Ensino", Skinner (1972) argumenta que a educação precisava se tornar mais eficaz. E, para tal, os currículos, os livros didáticos e as técnicas de ensino teriam de ser revistos e melhorados. De acordo com o entendimento do autor, o advento da televisão foi um dos fatores que contribuiu diretamente na revisão do uso de recursos audiovisuais na educação, visto que, para ele:

Os recursos audiovisuais suplementam e podem mesmo suplantar aulas, demonstrações e livros didáticos. Ao fazê-lo suprem uma função do professor: apresentam as matérias ao estudante e, quando o fazem bem, tornam-nas tão claras e interessantes que o estudante aprende (SKINNER, 1972, p. 27).

Não obstante a expressiva defesa de Skinner (1972) quanto ao uso de recursos audiovisuais na educação, o mesmo também se preocupava com o fato de que este equipamento poderia tornar o aluno um mero receptor passivo de informações. Era preciso haver, portanto, outro equipamento que ultrapassasse situações como essas, encorajando o aluno a participar ativamente do processo educacional. Skinner sugere um equipamento chamado "máquinas de ensinar", o qual levaria o aluno a testar sua inteligência e informações recebidas pelo professor em sala de aula. Estas máquinas foram pensadas, inicialmente, por Sidney L. Pressey, na década de 1920, e tinham o objetivo de não apenas testar e avaliar a aprendizagem dos alunos, mas também de ensiná-los (SKINNER, 1972).

As máquinas de ensinar de Skinner ou a instrução programada, como era variavelmente denominada, deveria ser elaborada pelos professores a partir de planos ou programas que previssem os comportamentos adequados a uma boa aprendizagem para qualquer aluno. A respeito disso, Pinto destaca que:

O programa assim ajustado substituirá com vantagens o professor na medida em que individualizará o ensino, tornando-o acessível a todos os alunos desde que cada um possa utilizar para o domínio das dificuldades o tempo adequado às suas necessidades (PINTO,1967, p. 273).

Não havia, portanto, uma preocupação com os diferentes ritmos de aprendizagens dos alunos. A ênfase estava na variação do tempo que cada um passava para adquirir o conhecimento, o que correspondia, por conseguinte, a uma preocupação com a variação comportamental do aluno.

Segundo Pinto (1967), na instrução programada o professor ocupava posição secundária no processo de aprendizagem. Ele tinha como principal objetivo apresentar um plano de instrução, mediante o qual surgiriam situações-problema objetivas e mensuráveis.

Revista HISTEDBR On-line, Campinas, n.43, p.92-102, set2011 - ISSN: 1676-2584 95 
Desse modo, caberia ao professor, no contexto da instrução programada, preparar o aluno para observar, ouvir, redigir, ler, memorizar e raciocinar ${ }^{11}$.

De modo geral, propostas pedagógicas como essas tinham em sua base a padronização do processo de ensino, pois, na medida em que se utilizava de estratégias como formas de alcançar a eficiência do trabalho pedagógico, não se preocupavam com a singularidade dos sujeitos envolvidos no processo. Assim, o meio, isto é, o recurso, desde que utilizado eficientemente, garantiria a aprendizagem do aluno.

Nessa perspectiva, os esquemas de planejamento previamente organizados pelos professores sofreriam apenas pequenos ajustes nas diferentes disciplinas e práticas pedagógicas, garantindo, de modo geral, a excelência dos resultados desejados no processo de aquisição do conhecimento pelos alunos. De acordo com Saviani,

Na pedagogia tecnicista o elemento principal passa a ser a organização racional dos meios, ocupando o professor e o aluno posição secundária, relegados que são à condição de executores de um processo cuja concepção, planejamento, coordenação e controle ficam a cargo de especialistas supostamente habilitados, neutros, objetivos, imparciais. A organização do processo converte-se na garantia da eficiência, compensando e corrigindo as deficiências do professor e maximinizando os efeitos de sua intervenção (SAVIANI, 2007, p. 382).

Do ponto de vista pedagógico, a questão central que o autor nos apresenta é de "aprender a fazer". Saviani (2007, p. 382), afirma que "na pedagogia tecnicista cabe ao processo definir o que os professores e alunos devem fazer, quando e como o farão". Assim, de acordo com tal entendimento, ocupando posição secundária no processo de ensino e aprendizagem, os professores são considerados meros aplicadores de técnicas facilitadoras do programa de aprendizagem, cabendo a eles, apenas auxiliar os alunos na execução das tarefas pré-estabelecidas.

Ao aluno, caberia, nesse sentido, à adequação aos meios e/ou técnicas educacionais que fazem parte do processo de aquisição do conhecimento. Desse modo, a aprendizagem de determinado conteúdo deveria ser transmitida de forma rígida e pré-programada, através de um conjunto de atividades oferecidas pelo professor e realizadas mecanicamente pelos alunos.

\section{O uso de recursos audiovisuais pela pedagogia tecnicista}

A pedagogia tecnicista, predominante no Brasil entre meados da segunda metade da década de 1960 e início de 1970, invocou a utilização de recursos audiovisuais na educação, sobretudo a TV, buscando instaurar um projeto de modernização no país e adequação às transformações tecnológicas. No reconhecimento dessas ideias, pretendemos trazer à baila das discussões as condições que viabilizaram, em certa medida, esse projeto de modernização social. Mas que condições foram essas? Quais as suas implicações para o campo da educação?

Ora, a resposta para tais questionamentos não parece ser algo tão simples, pois o uso de recursos audiovisuais na educação, à época, buscava, junto ao projeto de modernização social preterido, garantir também a modernização dos processos pedagógicos desenvolvidos nos espaços escolares e não-escolares brasileiros.

Conforme Miranda (1996), a tendência pedagógica tecnicista se preocupava em atender as novas necessidades produtivas do país, mediante a modernização dos recursos 
utilizados na educação (especialmente os meios de comunicação de massa), como forma de equiparar o sistema educacional ao estágio de desenvolvimento do setor produtivo do país. $\mathrm{O}$ autor afirma que o uso desses recursos na educação tinha como vantagem tornar o ensino mais eficiente e eficaz, promover estratégias de memorização do conteúdo e motivar os alunos envolvidos no processo de ensino e de aprendizagem. Nesse sentido, centrado no emprego eficiente e eficaz dos meios educacionais, estariam, dessa forma, garantindo a viabilidade de práticas educativas também eficientes.

Situado nessa discussão, Miranda (1996) identifica a coexistência de dois discursos que circulavam no âmbito educacional: o discurso da modernização do ensino, o qual concebia os meios de comunicação como o rádio, a televisão, o cinema e outros como instrumentos facilitadores da aprendizagem e o discurso democratizante do ensino, instaurado mediante o projeto de educação à distância no país.

No concernente ao primeiro discurso, entendemos que as transformações que sucederam no campo da ciência e da tecnologia no início do século passado, sobretudo o desenvolvimento dos meios de comunicação de massa, complexificaram ainda mais as relações sociais e as formas de disseminação do conhecimento, trazendo em seu bojo a necessidade de modernização do ensino como forma de adequação ao projeto de modernização das estruturas sociais que se vinha instaurando em nosso país.

No que tange o discurso democratizante do ensino, Miranda comenta que:

Os tecnocratas (afinados com a tendência tecnicista de educação) defendiam que, dado o estágio de desenvolvimento da educação escolar brasileira na época (década de 1960), dada as precariedades das condições de formação de educadores e devido à necessidade urgente de formação de mão de obra do país, os meios de comunicação poderiam se tornar o principal veículo de democratização da educação brasileira (MIRANDA, 1996, p. 121).

Com isso, incentivou-se a realização de projetos de educação à distância como forma de expandir o ensino e tornar acessível a educação à grande parte da população nãoescolarizada. Conforme Sousa (1969, p. 284), as estruturas políticas, culturais e sócioeconômicas da época impunham "a necessidade de mais e melhor ensino, a mais indivíduos e no mais curto prazo possível". Assim, a questão central era a de que ao mesmo tempo em que o país devesse caminhar rumo à modernização nos âmbitos social, político, econômico e cultural, também concretizasse o projeto de modernização no âmbito educacional.

Sousa (1969) argumenta que o projeto de modernização educacional do país estava subordinado ao uso dos meios de comunicação de massa na escola e, nesse sentido, a televisão, ganhava destaque principal. Segundo o autor, a escola não deveria se eximir de tomar uma posição e de buscar alternativas no qual se fizesse a seleção de certos conteúdos que circulavam na mídia televisiva para utilizá-los como instrumento em seu próprio benefício.

Ela (a escola) tem que inserir-se em seu meio social, em sua época, renovando, permanentemente, seu sistema de ensino [...]. Os mais poderosos meios de comunicação de massa - cinema, rádio, televisão devem constituir-se os melhores aliados da educação em nossos dias. Sobretudo a televisão (SOUSA, 1969, p. 285).

Revista HISTEDBR On-line, Campinas, n.43, p.92-102, set2011 - ISSN: 1676-2584 97 
A televisão para Sousa (1969) deveria estar a serviço da educação, adaptando-se às necessidades e recursos da atualidade. Segundo o autor, a utilização desse recurso no campo educativo apresentava como vantagem o grande número de alunos que poderiam ser alcançados através da emissora e a circulação de outros recursos audiovisuais e/ou sonoros, mediante os quais pudéssemos obter aprendizagens mais eficientes.

Assim, no que tange a concretização de um projeto de educação à distância no país, os programas para a TV Educativa (TVE), por exemplo, foram pioneiros. A primeira experiência ocorreu entre os anos 1950 e 1960, através de programas culturais ou educativos nas grandes cidades do país, a partir do qual foi lançado um programa de combate ao analfabetismo e um curso destinado aos alunos que tinham idade entre nove e onze anos, com o objetivo de prepará-los para os exames de admissão.

Um artigo publicado por Becker na Revista Brasileira de Estudos Pedagógicos, em 1967, relata as primeiras experiências da TVE no país, centradas, especialmente, na educação de adultos e na cultura popular. Conforme o autor, na cidade de Guanabara realizou-se um dos trabalhos mais significativos da TVE através da Fundação João Batista de Amaral.

Tratava-se de aulas trissemanais, de 50 minutos de duração, elaboradas por uma equipe de professores, empenhada em utilizar, com o máximo aproveitamento, os meios audiovisuais. Organizaram-se TV-Escolas e TV-Clubes em fábricas, igrejas, estabelecimentos de ensino, agremiações e sindicatos e em penitenciárias. Os alunos, assistidos por monitores, recebiam material didático preparado e distribuído pela Fundação, cabendo aos coordenadores a supervisão dos trabalhos. Os cursos incluíam as seguintes matérias: Linguagem, Matemática, Educação Sanitária, Noções básicas de Geografia, História, Cidadania, Economia e Ciência em geral (BECKER, 1967, p. 290).

A segunda experiência considerada inovadora no campo do ensino também ocorreu na cidade de Guanabara. Conhecida pelo título "Universidade sem paredes", reuniu-se uma equipe de educadores e artistas em um programa de extensão cultural, através do qual eram transmitidos cursos como a "História da Liberdade no Brasil", "Educação Familiar" e "Mistérios da Pintura Moderna" (BECKER, 1967). O autor ainda assinala a experiência vivenciada no Estado de São Paulo com a criação da Secretaria de Educação e TV-Cultura, canal 2, responsável por transmitir programas educativos por todo o Estado; a criação da SEFORT, responsável pela produção das apostilas do material didático e inscrição de escolas e alunos; a inclusão de programas na programação local de TV como o programa TV-Escola e a inauguração da TV Educativa na Universidade de São Paulo, utilizada, especialmente, como laboratório do curso de TV da Escola de Comunicações, realizado junto com os cursos básicos universitários.

Não obstante às experiências pioneiras da TVE em Guanabara e São Paulo, a proposta de educar através da TV se estendeu, aos poucos, para outros estados do país como Pará, Pernambuco, Paraná, Rio Grande do Sul, Rio de Janeiro, Minas Gerais e Distrito Federal. No entanto, a proposta pedagógica com o uso da TV não ficou apenas no âmbito da experiência, ela ganhou visibilidade em textos jurídicos a exemplo da Lei $\mathrm{n}^{\circ} .5$. 198 (BRASIL, 1967), que criou o Centro Brasileiro de Televisão Educativa, responsável pela produção, aquisição e distribuição do material audiovisual à radiodifusão educativa.

O Decreto $n^{\circ} .236$ (BRASIL, 1967), por sua vez, previu a reserva de canais para a TVE em todas as capitais dos Estados e cidades as quais tivessem população igual ou 
superior a 100 mil habitantes. Além disso, estipulou a obrigatoriedade da transmissão de programas educativos em emissoras comerciais, com duração máxima de cinco horas semanais, conforme podemos observar nos artigos $15^{\circ}$ e $16^{\circ}$ desta legislação:

$15^{\circ}$ Dentro das disponibilidades existentes ou que venha a existir, o CONTEL reservará canais de Televisão, em todas as capitais de Estados e Territórios e cidades de população igual ou superior a 100.000 (cem mil) habitantes, destinando-os à televisão educativa.

$16^{\circ}$ O CONTEL baixará normas determinando a obrigatoriedade de transmissão de programas educacionais nas emissoras comerciais de radiodifusão, estipulando horário, duração e qualidade desses programas (BRASIL, 1967).

Becker (1967) ressalta que apesar da criação de tais medidas governamentais, dando as condições legais para a realização da TVE no país, alguns fatores interferiram em seu desenvolvimento, como a indisponibilidade de recursos e equipamentos para realização em grande escala do que tinha sido previsto. Fato este que poderia ser solucionado, segundo o autor, mediante a destinação de uma parcela das finanças dos orçamentos da União e dos Estados para o desenvolvimento da TVE no país.

Outro fator, não menos importante, destacado por Becker (1967), refere-se à existência de poucas equipes técnicas especializadas no trabalho da TVE, favorecendo, segundo ele, a criação de um Centro de Treinamento deste pessoal.

Assunção (1969, p. 279) ressalta que no final da década de 1960 o quadro era praticamente o mesmo. Havia poucos educadores que trabalhavam com a TVE no Brasil, dentre os quais poucos possuíam formação adequada para o desenvolvimento da atividade.

Qualquer professor que deseje produzir uma aula para a TVE deverá conhecer primeiramente a televisão, seus impactos, sua linguagem, seus recursos e suas limitações, a fim de que a aula preparada alcance um resultado desejável. Assim, não basta transmitir um roteiro de aula a um técnico dotado de todos esses conhecimentos, pois só o professor, conhecedor do assunto, poderá fazê-lo eficientemente, desde que seja conhecedor da técnica da televisão. Por essa razão a importância de se difundir cursos de formação de professores para a TVE (ASSUNÇÃO, 1969, p. 279, grifo nosso).

Argumentos como esses, fazem-nos perceber que o domínio operacional da ferramenta audiovisual utilizada pelos professores em sala de aula se apresentava como condição sine qua non para a realização de um trabalho pedagógico eficiente. Trata-se, porém, a nosso ver, de uma visão instrumentalista da educação, uma vez que a ênfase do processo educacional recai sobre os meios educacionais e, tanto o professor quanto o aluno, assumem posições secundárias nesse processo.

Temos defendido, ao longo de nossos estudos, o uso pedagógico de recursos audiovisuais em sala de aula, em particular o filme, na perspectiva de ultrapassar uma visão instrumentalista, ilustrativa ou complementar do conhecimento. Com isso, pretendemos avançar para além da mera utilização do recurso audiovisual na educação (como fizeram os tecnicistas), pois compreendemos as imagens fílmicas como instrumentos que possibilitam a apropriação e a organização do conhecimento escolarizado pelos estudantes.

Revista HISTEDBR On-line, Campinas, n.43, p.92-102, set2011 - ISSN: 1676-2584 99 
Em síntese, as reflexões aqui delineadas nos servem para fortalecer a ideia de superação na atualidade do enfoque instrumental dos recursos audiovisuais, haja vista o desvencilhamento de uma visão reducionista da educação, que limita as possibilidades e potencialidade do uso pedagógico dos audiovisuais nas práticas pedagógicas.

\section{Considerações finais}

Gostaríamos de reafirmar, por fim, que a pedagogia tecnicista, assentada nas teorias do "capital humano" de Schultz (1967) e "comportamental" de Skinner (1972), procurou fortalecer a prática da racionalização do trabalho pedagógico, centrada nos meios educacionais e no uso eficiente de recursos audiovisuais na educação.

Assistimos, pois, a um debate ideológico e mecanicista da educação, uma vez que alguns educadores, influenciados pela tendência pedagógica tecnicista, enfatizavam o uso dos meios tecnológicos na educação, em particular a TV, como a panacéia que traria soluções para todos os males da metodologia e da didática da época, aliando-se, igualmente, ao projeto de modernização e transformações tecnológicas do país.

Para nós, entretanto, há necessidade de ultrapassar a visão instrumentalista e utilitarista do uso dos meios de comunicação na educação, bastante recorrente entre os educadores tecnicistas, os quais não tendo conseguido avançar, nesse sentido, limitaram-se a incorporação do recurso audiovisual nos processos pedagógicos como uma forma meramente ilustrativa, complementar do conhecimento e, estritamente, técnica.

\section{REFERENCIAS}

ASSUNÇÃO, José Teixeira de. Pedagogia e produção para a TVE. Revista Brasileira de Estudos Pedagógicos. Rio de Janeiro, v. 52, n. 116. p. 278 - 283, out./dez., 1969

BECKER, Gretchen. TV Educativa: Balanço das realizações e perspectivas. Revista Brasileira de Estudos Pedagógicos, Rio de Janeiro, v. 48, n. 108. p. 280 - 295, out./dez., 1967.

BRASIL. Lei n ${ }^{\circ} 5.540$ de 28 de novembro de 1968. Fixa normas de organização e funcionamento do ensino superior e sua articulação com a escola média, e dá outras providências. Diário Oficial [da] República Federativa do Brasil, Poder Executivo, Brasília, DF, v. 7, 29 nov. 1968. Seção I, p. 10369.

Lei $\mathrm{n}^{\circ} 5.692$ de 11 de agosto de 1971. Fixa Diretrizes e Bases para o ensino de $1^{\circ} \mathrm{e}$ $2^{\circ}$ graus, e dá outras providências. Diário Oficial [da] República Federativa do Brasil, Poder Executivo, Brasília, DF, 12 ago. 1971. Seção I, p. 6377.

Ministério da Educação. Conselho Federal de Educação. Parecer n ${ }^{\circ} .77$ de 11 de fevereiro de 1969. Regulamenta a implantação da Pós-Graduação no Brasil. Documenta, Brasília, DF, n. 98, p. 128-132, 1969.

Lei $\mathrm{n}^{\circ} 5.198$ de 3 de janeiro de 1967. Cria, sob a forma de Fundação, o Centro Brasileiro de TV Educativa. Diário Oficial [da] República Federativa do Brasil, Poder Executivo, Brasília, DF, 4 jan. 1967. Seção I, p. 113.

Revista HISTEDBR On-line, Campinas, n.43, p.92-102, set2011 - ISSN: 1676-2584 100 
. Decreto-Lei $\mathrm{n}^{\circ} 236$ de 28 de fevereiro de 1967. Complementa e modifica a Lei número 4.117 de 27 de agosto de 1962. Diário Oficial [da] República Federativa do Brasil, Poder Executivo, Brasília, DF, 28 fev. 1967. Seção I, p. 2432.

CAMBI, Franco. História da pedagogia. São Paulo: FEU, 1999.

FAHEINA, Evelyn Fernandes Azevedo. O uso de filme como estratégia mediadora da prática docente na educação de jovens e adultos. Trabalho de Conclusão de Curso. Centro de Educação/UFPB. João Pessoa-PB, 2010. Digitado.

FREITAG, Bárbara. Escola, Estado e Sociedade. São Paulo: Moraes, 1980.

GAL, Roger. Métodos ativos e recursos audiovisuais. Revista Brasileira de Estudos Pedagógicos, Rio de Janeiro, v. XLVI, n. 104. p. 316 - 320, out./dez., 1966.

MIRANDA, Carlos Eduardo Albuquerque. O que estamos vendo?: um estudo sobre imagem e educação na era da reprodutividade técnica. 1996, 138f. Dissertação - Curso de Mestrado em Educação, Faculdade de Educação, Universidade Estadual de Campinas, Campinas. Disponível em:

http://cutter.unicamp.br/zeus/auth.php?back=http://cutter.unicamp.br/document/?code=vtls 000111555\&go=x\&code=x\&unit=x. Acesso em: 01 Ago. 2010.

PINTO, Lília Sampaio de Sousa. Lugar do professor na instrução programada. Revista Brasileira de Estudos Pedagógicos, Rio de Janeiro, v. 48, n. 108. p. 271 - 279, out./dez., 1967.

ROMANELLI, Otaíza O. História da educação no Brasil (1930/1973). 27. ed. Petrópolis: Vozes, 2002.

SAVIANI, Demerval. História das idéias pedagógicas no Brasil. Campinas: autores associados, 2007.

SCHULTZ, Theodore W. O valor econômico da educação. Rio de Janeiro: Zahar, 1967.

Theodore W. O capital Humano: Investimentos em Educação e Pesquisa. Rio de Janeiro: Zahar Editores, 1973.

SKINNER, Burrhus Frederic. Tecnologia do ensino. São Paulo: Ed. Da Universidade de São Paulo, 1972.

SOUSA, Judith Brito de Paiva e. Intercâmbio e cooperação numa política para a TVE no Brasil. Revista Brasileira de Estudos Pedagógicos, Rio de Janeiro, v. 52, n. 116. p. 284 290, out./dez., 1969.

Revista HISTEDBR On-line, Campinas, n.43, p.92-102, set2011 - ISSN: 1676-2584 101 
Notas:

${ }^{1}$ Possui graduação em Pedagogia pela Universidade Federal da Paraíba (UFPB). É Mestranda em Educação pelo Programa de Pós-Graduação em Educação da UFPB e bolsista pela Coordenação de Aperfeiçoamento de Pessoal de Nível Superior (CAPES). E-mail: evelynfaheina@gmail.com

${ }^{2} \mathrm{O}$ modelo econômico associado-dependente, adotado no Brasil na época da Ditadura Militar, tinha como eixo central a doutrina da interdependência, cujo marco se dava na relação de interdependência entre o Ocidente e o Brasil. Saviani (2007) ressalta que na relação entre o Brasil e o líder do bloco ocidental, os Estados Unidos, havia uma relação de interdependência: “o que é bom para os Estados Unidos é bom para o Brasil" (p. 360).

${ }^{3}$ Theodore Schultz publicou no Brasil, em 1967, o livro “O valor econômico da Educação” e, em 1973, sob novo título "O capital humano: investimentos em educação e pesquisa".

4 Para aprofundamento da questão, consulte os artigos publicados na Revista Brasileira de Estudos Pedagógicos nas décadas de 1960 e 1970.

${ }^{5}$ Dentre as principais reformas do ensino que refletiram essa tendência temos: a Reforma Universitária instituída através da Lei $n^{\circ}$. 5.540, em 1968; o Parecer CFE $n^{\circ}$. 77/69, que regulamentou a implantação da Pós-Graduação no Brasil; o Parecer CFE nº. 252/69, que introduziu as habilitações técnicas no curso de Pedagogia e, finalmente, a aprovação da Lei $\mathrm{n}^{\circ}$. 5.692, em 1971, que culminou na disseminação da tendência produtivista em todas as escolas do país, por intermédio da pedagogia tecnicista, adotada como pedagogia oficial. De modo geral, as reformas do ensino preocupavam-se em ajustar a formação de mão-de-obra qualificada à lógica da sociedade capitalista. Para tanto, os meios educacionais compreendidos por: técnicas, instrumentos e metodologias deveriam estar pautados nos princípios da racionalidade, da eficiência e da produtividade, a fim de garantir a qualificação e a inserção das pessoas no mercado de trabalho (FREITAG, 1980; ROMANELLI, 2002; SAVIANI, 2007).

${ }^{6}$ Nessa perspectiva, caberia ao professor a mera aplicação de técnicas de aprendizagens e aos alunos a simplória adequação comportamental aos meios utilizados.

${ }^{7}$ Ao utilizarmos a expressão "recursos audiovisuais" no texto estaremos nos remetendo a quaisquer materiais e/ou formas de comunicação não escritas que invoque o registro de textos imagéticos e/ou sonoros, como as imagens televisivas, cinematográficas, etc.

${ }^{8}$ A expressão "qualidades ativas" refere-se ao sentido inovador que os recursos audiovisuais poderiam trazer para o campo da educação.

${ }^{9}$ Para aprofundamento da questão Cf. FAHEINA, 2010.

${ }^{10}$ Cf. GAL, 1966; PINTO, 1967; BECKER, 1967; ASSUNÇÃO, 1969; SOUSA, 1969.

11 Cf. PINTO, 1967.

Recebido em: 12/04/11

Aprovado em: $03 / 08 / 11$

Revista HISTEDBR On-line, Campinas, n.43, p.92-102, set2011 - ISSN: 1676-2584 102 